\title{
E. coli: The King Bacterium
}

\section{Girish B Mahajan ${ }^{1 *}$ and Dipali Rahul Phatak ${ }^{2}$}

${ }^{1}$ HiMedia laboratories Pvt. Ltd., Mumbai, India

${ }^{2} J o g e s h w a r i$ Education Society, Mumbai, India

*Corresponding Author: Girish B Mahajan, HiMedia laboratories Pvt. Ltd., Mumbai, India.

Received: June 06, 2019; Published: July 08, 2019

DOI: $10.31080 /$ ASMI.2019.02.0303

\begin{abstract}
E. coli, a gram negative bacterium, is one of the most well studied microbes in various aspects. Due to its ability of rapid growth, and simple and well studied DNA, it is used so extensively, that there is seldom any field of microbiology left where there is no application of this tiny microbe. Through a dramatic conversion between the bacterium $E$. coli and human, here is an attempt to bring major traits and applications of $E$. coli in view of our esteemed readers.
\end{abstract}

Keywords: E. coli; Bacterium; DNA

It was post-dinner time on Saturday. Sanju was alone; sitting at home watching science fiction movie. In fact Sanju was suffering from severe pain and discomfort in his stomach since past two days. Sanju was unable to tolerate the severe pain. Being a curious science student of higher secondary grade, he was wondering how a tiny, micron sized microorganism in stomach could cause so much trouble to humans that are 1.5 to 1.8 million times larger. Sanju arose to take an antibiotic, as prescribed by his family doctor the previous day. He took out the capsule from the pack, put it into the mouth and was about to drink water. And.....

Suddenly he heard a unique voice of different tone saying "Stop"...He was astonished to realize that the voice was coming from his stomach. He suddenly became alert and little scared. The voice said “Dear human, don't worry. I am a bacterium from your paining stomach".

Sanju replied in terror to that voice, "Bacterium?! from my stomach?! How can you speak little bacterium?"

Bacterium: "OK, OK, wait I will tell you everything to satisfy your curiosity. But for God's sake please don't take the antibiotic for some time. Else I shall die immediately as you humans have very powerful medicines".
Sanju composed himself, and asked in an inquisitive but surprised voice, looking at his painful tummy. "OK, for some time I will not take the medicine. Please tell me what you want to share. I am also wondering, how a tiny bacterium can make a human life so miserable".

The Bacterium replied in a soft and convincing voice, "I am a bacterium normally found in the human gut, scientifically referred to as the gastrointestinal tract. My scientific name is Escherichia coli and human lovingly call me E. coli. I belong to a very prestigious family of bacterial populations known as 'Enterobacteriaceae'”.

Sanju: "Oh you have family name as well, like my family name is 'Kulkarni””.

Bacterium: "Yes! In fact curious humans like you have studied our family very well and even our descendants too have been studied by humans. Very interestingly, humans named my colonial colleagues in the alimentary tract including me, as 'Coliform bacteria'. Sanju: "Wow you have families too! Tell me more about you".

Bacterium: "I would love to tell you all about us before I die from your antibiotic. There was a German-Austrian paediatrician, named Dr. Theodor Escherich, who was very inquisitive like you. 
In October 1884, Dr. Escherich went to Naples to do research work on the cholera epidemic. In 1885, he discovered me in the faeces of healthy individuals and named me as 'Bacterium coli commune' because I was found in the colon. He published the story of my discovery in a scientific monograph in 1886 at Stuttgart under the title, 'Die Darmbakterien des Säuglings und ihre Beziehungen zur Physiologie der Verdauung'.

Sanju: "Excellent discovery dear E. coli! Tell me how do you look?"

E. coli: "I look like a tiny stick. If you divide 1 centimetre into 10000 parts then my length is about 2-3 of such a tiny part (2-3 Micrometre). Girth is about 0.5 Micrometre. On the tip of a fine sewing needle we 100 to 150 friends easily stand for a selfie pose. We are visible only under microscope. Very interestingly I can double in number in just 20 minutes. Within 24 hours our number increases astronomically, almost equal to the potential number of galaxies in the universe. When we grow in a nutrient rich medium we produce visible spots called as 'colonies'. When we have food, water and some oxygen we start multiplying immediately. We are unique creatures where parents divide into 2 giving birth to 2 baby bacteria and parent bacterium disappears. On our whole body we have flagella and using those we actively run through any liquid medium to search for our food".

Sanju: "Oh very unique features you have E. coli. Are you male or female?"

E. coli: "We bacteria are very ancient and among the most primitive life on earth. It's difficult to identify us as male and female. However, some of my 'brothers' produce a special filament called "Pilus” (Plural: pili) and my 'sisters' don't produce it. These Pili are used for transfer of DNA and some other purposes. One of my interesting features is that I love milk sugar called lactose. I eat it and convert it to lactic acid. This trait has been used by humans for selectively detecting my presence in mixtures with other bacteria".

Sanju: "Pili, great to know about this". But you are a bad bacterium as you cause pain in human gut. Why do you do it?"

E. coli: "Dear human, in fact we E. coli are very innocent. We live happily and peacefully in the gut of humans and other animals and help humans. Sometimes in your gut, we have to compete very strongly with other competitive bacteria. 'Survival of the fittest' is rule of life. For competing with other bacteria we produce pow- erful chemical weapons (such as Shiga toxin, enterotoxin etc.) to kill our competitors. These weapons generally do not affect healthy humans. However if the human host is weak or already has other health issues and low immunity, they become sensitive to my chemical weapons and get affected, leading to diarrhoea (often known as travellers' diarrhoea). Hence we are called 'opportunistic pathogens.

Sanju: "Very true, I have become weak as I suffered from typhoid 2 months ago. So your chemical weapons have affected my gut and are causing pain, right?"

E. coli: "Yes. However, I confess that I have 6 cousins who are very dangerous for humans, Shiga toxin-producing E. coli (STEC), Enterotoxigenic E. coli (ETEC), Enteropathogenic E. coli (EPEC), Enteroaggregative E. coli (EAEC), Entero-invasive E. coli (EIEC), Diffusely adherent E. coli (DAEC)". One important thing I would like to share, if you humans do not complete prescribed dose of antibiotics then we develop a tolerance for the antibiotic and antibiotic resistant cousins are formed in your gut. They can be deadly for humans, at times.

"You humans should be careful as we can easily get transmitted through contaminated water or food, or through contact with animals or persons. This is the scary part. But a majority of my cousins are very useful and you intelligent humans have used us as a model in many biological studies".

Sanju: "Amazing, to hear this part. Tell me more about your applications in human life".

E. coli: "We are an important tool in biotechnology industry and are the most preferred organism by researchers to perform experiments in hereditary science. Our simple DNA, fast rate of growth, ease of handling, knowledge of our complete gene sequence, competency as a host, simple cultivation procedure and our ability to grow with and without oxygen distinguishes us from others in selection procedure for an experiment. We are currently used in production of insulin, anti-cancer protein drugs, biofuels, hydrogen and tryptophan; as biosensor in detection of toxic elements in water and air. We also have potential to use my genetically engineered cousin E. coli (called as E. chromi) in identifying various diseases like cancer and stomach ulcer soon. The list is endless. These are just a few key examples". 
Sanju: "E. coli, I am astonished to hear all your uses for us. You are really a King bacterium among the bacterial population. I salute you".

E. coli: "Thank you human. I feel relieved after sharing my information with you. Now I am ready for your antibiotic. I have troubled your stomach enough, sorry for that. Get well soon. I am happy hoping that soon my good cousin E. coli will occupy your stomach and see you healthy forever. Good bye human".

Sanju took the medicine and with a heavy heart said "Good bye, King Bacterium E. coli.

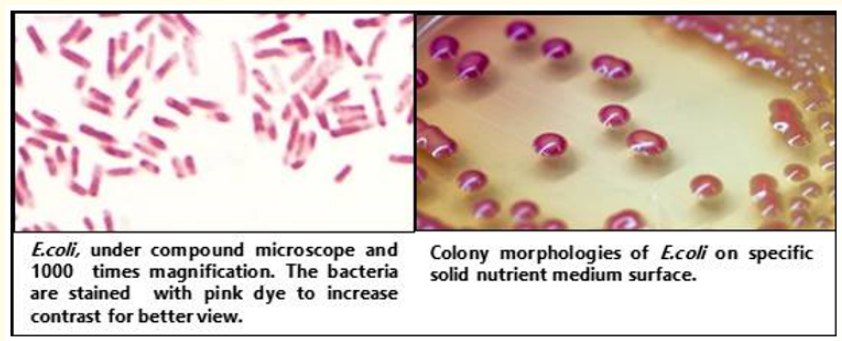

Figure 1

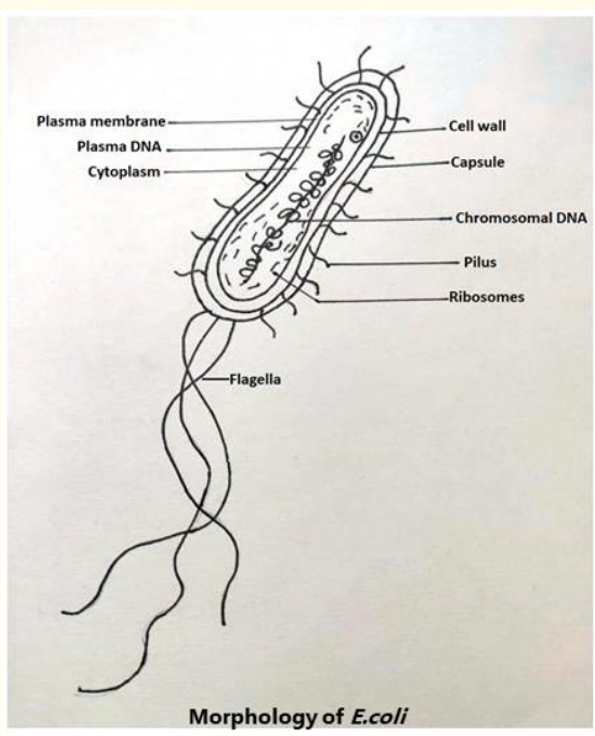

Figure 2

\section{Acknowledgment}

The authors are very thankful to their respective affiliation institutes for encouraging publishing of such awareness articles for wide readers of the journal. Authors of the article hereby gratefully acknowledge the Editor and Senior management of the monthly periodical titled 'Abhineet' published by 'Asha Foundation (https:// indiaasha.org/J' for approving the copyrights for the publication of the article, which was published in 'Abhineet' in May 2019 issue.

\section{Volume 2 Issue 8 August 2019 \\ (C) All rights are reserved by Girish B Mahajan and Dipali Rahul Phatak.}

